\title{
Implementing Mobile Technology on Construction Sites: An Ethnographic Action Research Approach
}

\author{
Éric St-Pierre, Conrad Boton ${ }^{(\bowtie)}(\mathbb{D}$, and Gabriel Lefebvre \\ École de technologie supérieure, 1100, rue Notre-Dame Ouest, Montreal, Canada \\ conrad.boton@etsmtl.ca
}

\begin{abstract}
The increasing dissemination of the Building Information Modelling (BIM) approach must not overshadow the fact that many firms are still far from BIM, and are in fact just starting out on the road to adopting information technologies. This paper presents an ethnographic action research study conducted with an industrial partner that decided to implement information technologies on its construction sites, with a strong preference for home-made applications. The results suggest that firms lack the internal expertise to effectively conduct such development work. Thus, the passage of needs expressed by the firm towards the development of the application is particularly difficult and the pivotal role of the researcher was crucial in the success of the project. Multiple iterations and versions were necessary before achieving the expected goals.
\end{abstract}

Keywords: Mobile computing - Mobile cloud computing · Information technology for construction $\cdot$ Construction site $\cdot$ Ethnographic action research

\section{Introduction}

In the last decades, the construction industry has undergone a digital transition, manifested in particular by the growing role of information technology (IT) in practices [1-3]. In this context, the BIM approach appears to occupy an important place, and several works have shown its added value and its uses at different stages of a construction project [4]. Several studies have also shown that BIM is increasingly being disseminated in architectural, engineering and construction firms, and that the point of no return has been reached $[5,6]$. However, this reality should not overshadow the fact that several firms are still far from BIM, and are in fact just beginning their adoption of information technologies [2]. The situation with general contractors and subcontractors is more challenging because the adoption of IT in the office must be accompanied by a similar adoption of mobile technologies on construction sites, in order to optimize information exchange between the office and the construction site [7].

Experiences reported in the literature show that the adoption of mobile technologies on-site can be more difficult, and poses significant challenges, due to the peculiarities and particular requirements of construction site work. Thus, the research on the subject 
is often based on generic solutions [8,9], and is limited to the study of related issues $[10,11]$, the link with BIM and the ability of site actors to adapt their work processes to these tools [12-15], and the study of perceived added value [16-20]. Very few studies [14] have explored the issue using a participatory approach to identify the real needs of firms, their ability to meet their own needs with their in-house resources, and the issues associated with their decisions. The research presented in this article took place at the premises of an industrial partner which decided to implement information technologies on its construction sites, with a strong preference for home-made applications. The objective of the research is to understand the internal dynamics allowing proceeding from the initial situation of the firm and the needs expressed, towards a solution adapted to the realities of its construction sites.

The article is organized into four main parts. The first part presents related works. The second part introduces the methodology. The third part presents the context and the main results. The fourth part concludes the paper and presents the future works.

\section{Related Works}

\subsection{Information Technology in the Construction Industry}

Two main flows appear in the production chain of a construction activity, as proposed by Sunke [21]: the flow of material and the flow of information, with strong interactions between the two. These flows correspond to the two major sub-processes identified by Bjork [22], namely, the information sub-process and the hardware subprocess. The material sub-process is the more tangible of the two, but needs the information sub-process, since, along with material and energy, information is the third fundamental component of sociotechnical systems [23]. Information Technology (IT) can be defined as "the use of electronic machines and programs for the processing, storage, transfer and presentation of information" [22]. The formats commonly used to represent information in construction are text documents, 2D and 3D drawings, schedules in bar chart and other formats, various diagrams and charts, tables, etc. The solutions to construction project problems are highly dependent on the experience and judgment of professionals and involve uncertainties. These barriers to applying IT in architecture, engineering and construction (AEC) lead to a challenging and interesting problem when it comes to producing an inventory of the use and the impact of IT on the industry.

Debate on the subject focuses on the premise that while demand actually exists, current technology-based solutions proposed to the industry are not adapted enough to support current needs [17, 24]. According to Bowden et al. [17], those involved in the development of such systems tend to focus on what is technically exciting and on what presents great challenges, rather than on the real needs and issues facing construction companies. Several other factors could also be raised as contributing to delays in the use of information technology; these factors can in fact be considered as barriers to adoption. Based on Bowden et al. [17], we can summarise the factors as follows: lack of leadership, resistance to change, fragmentation of the industry, difficulty of use and lack of internal competencies. 


\subsection{Mobile Computing for Construction Sites}

According to Rebolj and Menzel (2004), because of its specific characteristics, the architecture, engineering, construction (AEC) industry is a very good field for the implementation of mobile computing. They defined mobile computing through three main components: (1) computers usable while being in motion, excluding conventional notebooks; (2) networks with enough bandwidth accessible while in motion; (3) mobile applications to support personalisation and context sensitivity [25]. Mobile information technology then includes "tablet PCs and all kinds of pocket computers $[\ldots]$ and wearable computers" [25], aims to enable workers to "to roam seamlessly with computing and communication functionalities in an uninterrupted way" [9]. Its deployment has been enabled in different industries by the development of "affordable mobile technologies", making it common for mobile users to "capture, store and reuse information" [17]. Rebolj and Menzel (2004) argued that mobile computing is not just another information technology, but a very important factor in construction, with the potential "to increase the effective use of IT in an integrated and holistic way" [10]. Indeed, mobile computing can "extend the boundary of information systems from site offices to actual work sites and ensure real-time data flow to and from construction work sites" [10].

Nowadays, technology has evolved dramatically, and most of the preceding issues are no longer as pertinent. Mobile cloud computing has considerably increased mobile device computing resources [26]. It combines cloud-based storage and application processing services to improve compute-intensive applications and off-device storage on mobile devices. This computing can implement multiple strategies of augmentation (storage, screen, energy, application processing) in order to alleviate the resource limitations of traditional mobile computing systems [26, 27]. It can thus significantly reduce the cost of mobile application development and execution, while greatly extending the resources and the services provided [28]. Abolfazli et al. (2014) proposed a comparison between cloud-based computing and traditional resources, showing that cloud-based systems ensure higher computational power, elasticity, user experience, reliability, security and safety. Many recent research works have explored the question of the use of mobile computing on construction sites. Some of them have studied the use of mobile apps on construction sites, focusing on the added value brought to construction projects $[16-18,20]$, or on extending the uses of BIM on construction sites, using mobile cloud computing [13-15].

\section{Research Approach}

Action research is a research approach based on the belief that it is by acting first and foremost that scientific data can be collected [29]. is a method that prioritises practice and collaboration between practitioners and researchers throughout the project process. However, it does not necessarily offer tools and techniques to allow a good understanding of the process. Ethnographic research proposes these tools and techniques for research. It was developed by anthropologists for the study of human culture, but in recent decades, it has been used as an instrument of observation for the implementation 
of technologies in systems. Ethnographic action research focuses on understanding the actions, thoughts and feelings of professionals, throughout their work day. This makes it possible to implement customised systems that are tailored to meet their real needs, using the ethnographic action research approach as proposed by Hartmann et al. (2009). This type of research must draw information from several sources, such as existing and completed forms, interviews, observations, reports, etc. To be possible, it requires a good integration of the researcher into the project team. After all the information is gathered, it will be possible to determine and design a platform adapted to the needs. With ethnographic action research, it is important to always be able to compare results with the initially identified needs [30].

In this research, we use the ethnographic action research principle explained above. Observations, internal documentation reviews and interviews are conducted in order to understand the business context and to identify the needs. The appropriate solutions are then proposed according to these needs, and implemented in a pilot project, to evaluate the proposals. The choice of the device was conducted in 3 steps. First, a list of requirements was established, based on the previously identified need. In the light of these requirements, the researcher prepared a shortlist of devices that potentially meet the needs. Working with the internal developers, additional criteria were then used to preselect the most appropriate devices. Finally, discussions with upper management and the operational workers led to the choice of one device.

\section{Main Results}

\subsection{The Context}

The industrial partner is a steel structure company that has been operating in the field for 40 years. It manufactures and installs steel frames, and in some cases, can offer design services. When fully operational, the firm employs close to 150 people. Although cell phones and e-mails are widely used in the firm for communication, paper is still present, and is the most used tool for management by project managers. This is also the reality for the many projects carried out by the company, which therefore leads to significant information duplication. Indeed, the use of paper is still a necessity as it allows forepersons and superintendents to do their work, including the management of incoming information from forepersons and clients (drawings, training plans, health and safety sheets, daily reports, inspection sheets, additional worksheets, etc.). The most illustrative example of the importance of paper and the duplication of information is related to management of the overtime worksheets. Once the overtime worksheets have been completed by the superintendent or the coordinator at the end of the day, the superintendent must sign them and send them to the client for approval and signature. After signing, he must scan and email them to the project manager. Then, he must place them in an envelope which will be mailed to the central office which keeps the original copies in dedicated folders. Whenever things have to be verified by the project manager before the client's signature, the process time is significantly extended. 
Following the study of the internal documentation, observations of real-life experiences in the field, and interviews with stakeholders, the most important needs were identified in order to understand the current processes of the company and the review of the literature; these needs were related to information sharing and communication, access to information and simplification of existing processes, the mobility and the durability of tools, and increased productivity. More specific needs, such as those relating to the technology choice (hardware and software), helped to better guide the final decision and meet the needs of the company. Particular attention was paid to the work environment and the harsh construction site conditions. The selected hardware then had to meet the durability, strength and versatility requirements, in addition to more conventional requirements such as known operating system, and storage capacity.

\subsection{Choosing the Mobile Device and Designing the Application}

Ten tablets were selected and compared. The comparison elements are presented in Appendix A. Only three technologies most corresponding to the identified needs were chosen. The first was from Dell, the Latitude 7212 Rugged Extreme tablet. It meets all the needs presented above. However, it comes with a high price tag. The second is the FZ-G1 tablet, from Panasonic. Like the first tablet, it also meets all identified needs and has a slightly high price. The third one is the ET50/55 tablet from Zebra. Of the three products, it presents the most advantageous price for what it can offer as characteristics. The final choice was the Dell Latitude 7212 Rugged Extreme. The reason was simply a matter of availability. The Panasonic is more difficult to obtain and a contact at Dell facilitated communications. The final price for the technology was \$3500 Canadian dollars, including a scanner module and an interchangeable battery.

The design of the application was the part that required the most effort as compared to the other aspects of the project. As a result, not all of the originally planned functionalities were included in the final solution. Four functionalities were initially selected in relation to the current context and needs: the daily job site report, time sheets for workers, overtime worksheets, and access to PDF drawings. The application was designed in three complementary and iterative phases, namely, Balsamiq mock-ups; a first development phase, with QT Creator; and a second design phase, with Delphi. The project team evaluated the results of the first version of the platform designed using QT Creator, and was not happy with the results. This first interface was then abandoned. A second attempt was made with QT Creator, using QML, a derivative of HTML that allows for more mobile-friendly applications. However, only one person in the team had knowledge of this language. This made for a difficult and time-consuming development (with QML), and once again, the decision was made to abandon the application created with QT Creator. After the failure of the first versions of the application, created with QT Creator, a decision was made to use the program with which most of the company's platforms are made, namely, Delphi. The team has advanced knowledge of Delphi, and as a result, the development of the platform could be faster. In addition, in order to have a stable application in a timely fashion, it was decided to limit the scope of the project to the daily site report requirements. 


\subsection{The Final Version of the Application}

The development of the final version of the application was done based on the UML class diagram presented in Fig. 1. When the application is launched, the main menu is displayed. Using the three-line symbol on the top left corner, the user can navigate through the different pages of the application. Back on the team composition page, several teams can be created simply by selecting the names of the people who will compose the teams, proceeding by column. These teams will be retained in memory, so the user can quickly enter the team associated with an activity in the daily report. A person can also be removed from or added to an activity in the daily report. It was decided to compose teams in this fashion because the company's site employee database can easily be linked to the application. Consequently, when new employees are added to the human resources database, it is automatically updated.

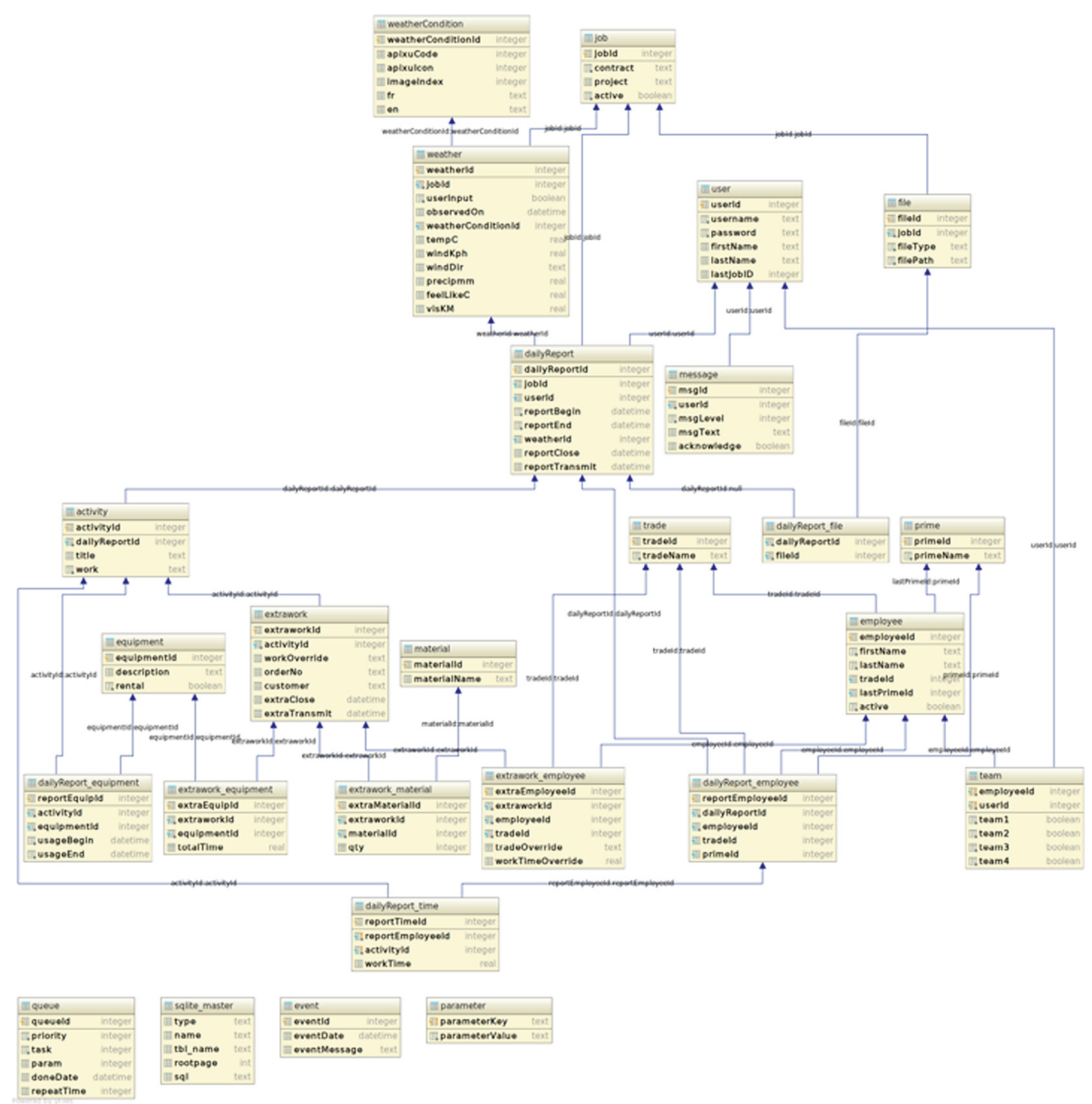

Fig. 1. UML class diagram of the data management process in the application 
When a report is created, it automatically appears in the opening menu of the daily reports. Here, the date of the report is shown, along with the number of total hours worked for the day, the report status and the user who created it. The report can be modified or deleted. When entering the daily report interface, the first thing the user sees is the main menu. All reports are shown and options are provided to create a new report, or to edit or delete a selected one. The user can also navigate through time to see past reports.

Figure 2 shows how the site report interface is organised. Section marked 1 in Fig. 2 allows the user to enter the date and the time. Here, the user can also obtain information about the weather, since it can have a significant impact on the team's performance. Section 2 summarises the activities conducted during the work day. Each activity must be entered as a separate item in the application. Workers and hours can be associated to activities. On the far right, a summary of activities is found, along with associated hours. Section 3 allows the workers to author the daily report, including the daily activities and the worked hours. This allows having the right people and the right hours for the overtime worksheets (extra work). In addition, the job of each worker is indicated, as well as whether a bonus is attached to the work performed (e.g., for the group leaders). Section 4 allows the user to log all the equipment that was used during the day. This section is important for extra work, to indicate the duration of a piece of equipment usage.

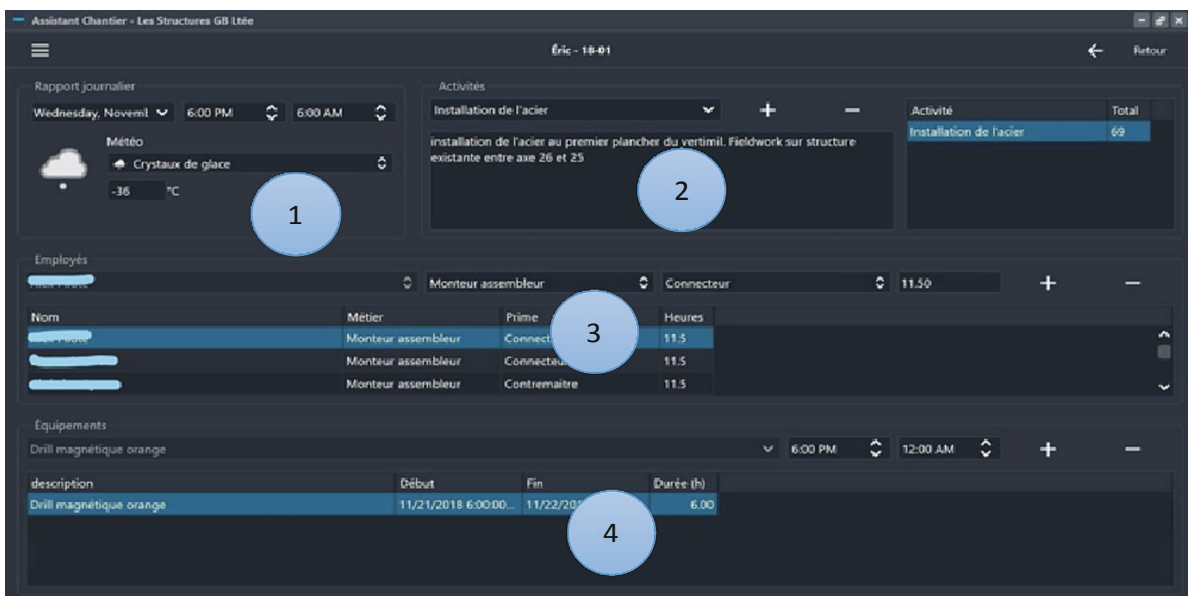

Fig. 2. Daily site report interface

\section{Conclusion and Future Works}

The research reported in the present paper provides a new perspective of the difficulties construction firms can face as they move to implement information technologies on their construction sites. It is very interesting to see how, despite the fact that many stable commercial applications exist, some firms prefer to rely on in-house competencies to 
develop their own applications. The study shows that developing such applications can be particularly challenging, with the need to have multiple iterations and failures before achieving the expected goals. In the case studied in this research, the initial needs evolved considerably throughout the application development and evaluation process. Finally, the project had to focus on only a part of the initial needs and to postpone the others for future work.

Future works will present the evaluation process of the technology and the feedbacks from the site team.

\section{References}

1. Samuelson, O., Björk, B.-C.: A longitudinal study of the adoption of IT technology in the Swedish building sector. Autom. Constr. 37, 182-190 (2014)

2. Kubicki, S., Boton, C.: IT barometer survey in Luxembourg: first results to understand IT innovation in construction sector. In: Computing in Civil and Building Engineering, pp. 179-186. American Society of Civil Engineers, Orlando (2014)

3. Boton, C.: Use and impact of information technology in the African construction industry: a preliminary survey from Benin. In: Adjallah, K.H., Birregah, B., Abanda, H.F. (eds.) ICEASSM 2017. LNNS, vol. 72, pp. 411-418. Springer, Cham (2020). https://doi.org/10. 1007/978-3-030-13697-0_31

4. Sacks, R., Eastman, C., Lee, G., Teicholz, P.: BIM Handbook: A Guide to Building Information Modeling for Owners, Designers, Engineers, Contractors, and Facility Managers. Wiley, Hoboken (2018)

5. Jung, W., Lee, G.: The status of BIM adoption on six continents. Int. J. Civ. Struct. Constr. Arch. Eng. 9, 406-410 (2015)

6. Kassem, M., Succar, B.: Macro BIM adoption: comparative market analysis. Autom. Constr. 81, 286-299 (2017)

7. Ahn, Y.H., Kwak, Y.H., Suk, S.J.: Contractors' transformation strategies for adopting building information modeling. J. Manag. Eng. 32, 05015005 (2016)

8. Chen, Y., Kamara, J.M.: Using mobile computing for construction site information management. Eng. Constr. Arch. Manag. 15, 7-20 (2008)

9. Anumba, C.J., Wang, X.: Mobile and pervasive computing in construction: an introduction. In: Mobile and Pervasive Computing in Construction, pp. 1-10 (2012)

10. Chen, Y., Kamara, J.M.: A framework for using mobile computing for information management on construction sites. Autom. Constr. 20, 776-788 (2011)

11. Yeh, K.-C., Tsai, M.-H., Kang, S.-C.: On-site building information retrieval by using projection-based augmented reality. J. Comput. Civ. Eng. 26, 342-355 (2012)

12. Kimoto, K., Endo, K., Iwashita, S., Fujiwara, M.: The application of PDA as mobile computing system on construction management. Autom. Constr. 14, 500-511 (2005)

13. Davies, R., Harty, C.: Implementing "site BIM": a case study of ICT innovation on a large hospital project. Autom. Constr. 30, 15-24 (2013)

14. Svalestuen, F., Knotten, V., Laedre, O., Professor, A.: Using building information model (BIM) devices to improve information flow and collaboration on construction sites. J. Inf. Technol. Constr. (ITcon) 22, 204-219 (2017)

15. Park, J., Cho, Y.K., Kim, K.: Field construction management application through mobile BIM and location tracking technology. In: International Symposium on Automation and Robotics in Construction, pp. 83-89 (2016) 
16. Marsh, L., Flanagan, R.: Measuring the costs and benefits of information technology in construction. Eng. Constr. Arch. Manag. 7, 423-435 (2000)

17. Bowden, S., Dorr, A., Thorpe, T., Anumba, C.: Mobile ICT support for construction process improvement. Autom. Constr. 15, 664-676 (2006)

18. Hasan, A., Jha, K.N., Rameezdeen, R., Ahn, S., Baroudi, B.: Perceived productivity effects of mobile ICT in construction projects. In: Mutis, I., Hartmann, T. (eds.) Advances in Informatics and Computing in Civil and Construction Engineering, pp. 165-172. Springer, Cham (2019). https://doi.org/10.1007/978-3-030-00220-6_20

19. Omar, T., Nehdi, M.L.: Data acquisition technologies for construction progress tracking. Autom. Constr. 70, 143-155 (2016)

20. Forcada, N., Macarulla, M., Bortolini, R.: Using a mobile application to assess building accessibility in smart cities. In: eWork and eBusiness in Architecture, Engineering and Construction: ECPPM 2016: Proceedings of the 11th European Conference on Product and Process Modelling (ECPPM 2016), Limassol, Cyprus, 7-9 September 2016, p. 277 (2017)

21. Sunke, N.: Planning of construction projects: a managerial approach (2009)

22. Björk, B.-C.: Information technology in construction-domain definition and research issues. Int. J. Comput. Integr. Des. Constr. 1, 1-16 (1999)

23. Ahmad, I.U., Russell, J.S., Abou-Zeid, A.: Information technology (IT) and integration in the construction industry. Constr. Manag. Econ. 13, 163-171 (1995)

24. Boton, C., Kubicki, S., Halin, G.: Designing adapted visualization for collaborative 4D applications. Autom. Constr. 36, 152-167 (2013)

25. Rebolj, D., Menzel, K.: Mobile computing in construction. J. Inf. Technol. Constr. 9, 281283 (2004)

26. Silverio, M., Renukappa, S., Suresh, S., Donastorg, A.: Mobile computing in the construction industry: main challenges and solutions. In: Benlamri, R., Sparer, M. (eds.) Leadership, Innovation and Entrepreneurship as Driving Forces of the Global Economy. SPBE, pp. 85-99. Springer, Cham (2017). https://doi.org/10.1007/978-3-319-43434-6_8

27. Abolfazli, S., Sanaei, Z., Ahmed, E., Gani, A., Buyya, R.: Cloud-based augmentation for mobile devices: motivation, taxonomies, and open challenges. IEEE Commun. Surv. Tutor. 16, 337-368 (2014)

28. Ahmed, E., Gani, A., Sookhak, M., Hamid, S.H.A., Xia, F.: Application optimization in mobile cloud computing: motivation, taxonomies, and open challenges. J. Netw. Comput. Appl. 52, 52-68 (2015)

29. Brydon-Miller, M., Greenwood, D., Maguire, P.: Editorial: Why Action Research? Action Res. 1, 9-28 (2003)

30. Hartmann, T., Fischer, M., Haymaker, J.: Implementing information systems with project teams using ethnographic-action research. Adv. Eng. Inform. 23, 57-67 (2009) 